\title{
Polymorphic fingerprint as an approach to authenticate Iberian pig categories
}

\author{
Laura Bayés-García • | Eduard Colomer-Llombart | Mercedes Aguilar-Jiménez | \\ Teresa Calvet
}

Departament de Mineralogia, Petrologia i Geologia Aplicada, Facultat de Ciències de la Terra, Universitat de Barcelona, Barcelona, Spain

\section{Correspondence}

Laura Bayés-García, Departament de Mineralogia, Petrologia i Geologia Aplicada, Facultat de Ciències de la Terra, Universitat de Barcelona, Martí i Franquès, s/n, 08028

Barcelona, Spain.

Email: laurabayes@ub.edu

Funding information

ALBA synchrotron, Grant/Award Number: 2014070991; Ministerio de Economía y Competitividad, Grant/Award Number: MAT2015-65756-R

\begin{abstract}
High-commercial-value products are often susceptible to food fraud. Among them, Iberian dry-cured ham is highly appreciated due to its particular and sensory, but also nutritional, properties. There are four different Iberian ham categories (namely bellota, recebo, cebo de campo and cebo), which directly depend on the rearing system of the pig during the last stage of the fattening phase. However, there is still a lack of a normalized and robust method capable of authenticating the different product categories and, therefore, preventing mislabeling. In the present work, we characterized the polymorphic behavior of raw (before curing) lipid extracts belonging to the four categories of Iberian pig. A total of 80 different samples were analyzed by DSC, and synchrotron radiation XRD experiments were carried out for selected ones. The results obtained showed that bellota and recebo categories exhibited essentially the same crystallization and polymorphic behavior and this was significantly different $(p<0.05)$ from that of cebo de campo and cebo. The latter exhibited higher crystallization and melting temperatures than bellota and recebo samples, due to the occurrence of an additional $\beta^{\prime}-2 \mathrm{~L}$ polymorphic form. By considering the differences in rearing systems of pigs belonging to the different categories, we concluded that the key factor which determined the polymorphism of Iberian pig lipid extracts was not the physical exercise practiced by the pig, but the inclusion of acorns in the feeding system. This work demonstrated that thermal and crystallographic techniques, like DSC and XRD, may be promoted to be used as fingerprinting tools for the authentication of high-value food products.
\end{abstract}

\section{KEYWORDS}

authentication, crystallization, differential scanning calorimetry, Iberian pig, polymorphism, synchrotron radiation, $\mathrm{X}$-ray diffraction

\section{INTRODUCTION}

The problem of food adulteration is by no means a contemporary phenomenon and is likely to be as old as the food processing and production systems themselves (Ellis et al., 2012). Authentication of food products is of primary importance for consumers and industries at all levels of the production chain. The adulteration of food products normally becomes a means for fraudulent economic gain, as fraudulent actions are commonly applied to high-commercialvalue products or to those which are produced in high tonnage. Foodstuff, such as jam, fruit juice, meat, honey, milk, wine or vegetable oils are often adulterated with the addition of cheaper products, dilution processes or mislabeling (Cordella et al., 2002). 
Nevertheless, the detection of adulterations or the discrimination between different product categories become a very complicated issue when chemical compositions are similar.

Several methodologies have been used for foods authentication, such as spectroscopic techniques, methods based on mass spectrometry, chromatography or calorimetry. Characteristics of spectroscopic techniques are their rapidity and portability, and they can provide the fingerprint of a food product. On the other hand, calorimetric techniques, such as differential scanning calorimetry (DSC), are also rapid and highly sensible, and they can show the authenticity of a food product or the effect of an adulteration on the physicochemical properties of the sample (Chiavaro, Rodriguez-Estrada, et al., 2008a; Chiavaro, Vittadini, et al., 2008b).

Among high-commercial-value products, traditional Spanish Iberian dry-cured ham is greatly appreciated for its particular and intense sensorial characteristics and associated with top quality gastronomy worldwide. Mainly produced in the southwest regions of Spain, Iberian pigs (pure breed or crossed with Duroc) are raised according to different systems, so that their dry-cured products are classified into different commercial ranks. Four are the categories of Iberian pigs, namely bellota, recebo, cebo de campo and cebo. Although according to the current Spanish legislation (Royal Decree $4 / 2014,2014$ ), recebo has been eliminated and, therefore, nowadays three are the existing categories (bellota, cebo de campo and cebo), it is of primary importance to characterize all of them in order to find a robust method to authenticate the product and prevent fraudulent practices. Regarding the rearing systems which define each Iberian pig category, Table 1 summarizes their characteristics and requirements.

Bellota products, which are the most appreciated due to its sensory attributes, and also those of highest commercial value, come from pigs with a final fattening period in oak forests (period called montanera) during which they exclusively eat acorns, grass and other natural resources. Then, the minimum duration of this period is 60 days and the minimum weight gain of the pig must be of $46 \mathrm{~kg}$. Recebo products are obtained from pigs that combine the consumption of acorn and grass with a supplementation of concentrated feeds (minimum duration of montanera: 60 days; minimum weight gain: $29 \mathrm{~kg}$ ). By contrast, cebo de campo and cebo products come from pigs fed with commercial feeds throughout their life. However, in the case of cebo de campo, pigs roam in pasture for at least 60 days prior to slaughter, although they keep eating mainly commercial feeds. The differences in animal nutrition in the final stage of the fattening period may determine the sensory quality of final products, due to different lipid deposition in adipose tissue and intramuscular fat (Tejeda et al., 2002). As a consequence, both sensory properties and commercial value increase following the sequence: cebo-cebo de campo-recebo-bellota.

Several methods have been used to discriminate among different lberian dry-cured ham of different categories. Almost all the procedures are based on fat properties, such as melting and slip point, or fatty acid profiles. These methods rely on the fact that bellota usually contains higher amounts of oleic acid than other categories (Ruiz et al., 1998). By contrast, other methods include the determination of hydrocarbons (Narváez-Rivas et al., 2008) and volatile compounds profiles (Narváez-Rivas et al., 2011; Timón et al., 2001). Moreover, isotope analyses on the adipose tissue of the animals have also been applied to characterize and differentiate lberian pork meat as a function of the diet of the animal (González-Martin et al., 1999). As to spectrometric techniques, nearinfrared spectrometry (NIR) has also been used with the same purpose (Arce et al., 2009), although this method could not perfectly discriminate among the different pig categories. Recently, more attention has been paid to the determination of the TAGs composition, as analyses become easier and faster, avoiding the use of saponification and the formation of methyl esters (Diaz et al., 1996; Gallardo et al., 2012). The TAGs composition has also been determined to elucidate the effect of genotype (Petrón et al., 2004; Tejeda et al., 2002; Viera-Alcaide et al., 2008). However, there are still some ambiguities in the results obtained by the methods used until now when high amounts of samples have been analyzed.

T A B LE 1 Characteristics of final period of fattening phase of Iberian pig categories

\begin{tabular}{|c|c|c|c|c|c|}
\hline Iberian pig category & Feeding system & $\begin{array}{l}\text { Minimum duration } \\
\text { of montanera } \\
\text { (days) }\end{array}$ & $\begin{array}{l}\text { Minimum weight } \\
\text { gain in } \\
\text { montanera }(\mathrm{kg})\end{array}$ & $\begin{array}{l}\text { Minimum age prior } \\
\text { to slaughter } \\
\text { (months) }\end{array}$ & $\begin{array}{l}\text { Sensory qualityl } \\
\text { commercial value }\end{array}$ \\
\hline Recebo & $\begin{array}{l}\text { Acorns, grass, other } \\
\text { natural resources, } \\
\text { commercial feeds }\end{array}$ & 60 & 29 & 14 & High \\
\hline Cebo & Commercial feeds & - & - & 10 & Lower \\
\hline
\end{tabular}


Although the purpose of the new Spanish regulation consists of protecting the purity of Iberian pig, controlling the breeding and feeding and properly labeling the final product, there is still a lack of a normalized and robust method to discriminate among the different categories.

Some studies have focused on the characterization of physical properties of pork fat. Svenstrup et al. (2005) analyzed the influence of changing the cooling and reheating rates applied to pork fat. By using DSC and XRD techniques, they characterized samples of lard (pork dorsal fat) and leaf pork fat (surrounding the kidneys) in their raw state, their extracted fat fraction, and in liver pâté. The crystallization behavior observed permitted defining the textural properties when pork fats were used in liver pâté. Campos et al. (2002) also applied different cooling rates to lard samples, but in order to observe the effects of such variations on the hardness of fat crystal networks. By contrast, Davenel et al. (1999) studied solid fat content variations of pig adipose tissues in relation to their lipid composition. As to spectroscopic techniques, Raman spectrometry has been employed to in situ analyze the crystalline states of fat in porcine adipose tissue (Motoyama et al., 2013). The purpose was to establish a tool for routine monitoring the physical conditions of meat carcasses in refrigerators. The same technique was also proposed to discriminate between pork and beef fat, by analyzing the polymorphic features of the characterized samples (Motoyama et al., 2010).

Our group has recently studied the polymorphic behavior of the two most differentiated categories of Iberian dry-cured ham (bellota and cebo), and obtained very promising results (Bayés-García et al., 2016), as significant differences, related to the polymorphic behavior of the samples, were detected and permitted to clearly discriminate among the two categories. Differential scanning calorimetry (DSC) and X-ray diffraction (XRD, with both laboratory-scale or synchrotron radiation source) have been widely used to study the polymorphism of lipid systems, in order to characterize their physical properties, such as melting, morphology, rheology and texture (Bayés-García et al., 2020; Larsson et al., 2006). Nevertheless, these techniques have been rarely used in food authentication.

In the present work we used DSC and XRD techniques to study the polymorphic behavior of the four Iberian pork categories, including intermediate recebo and cebo de campo to make a step further. Moreover, we used raw lipid samples, obtained before the curing of the ham, to define a more robust method, as curing becomes a very complex procedure in which it is not possible to control the variables which may modify the behavior of the samples. The aim of this study is not the validation of a method, as we are aware that a significantly higher amount of samples may be analyzed and its corresponding statistical analysis may be carried out. However, it demonstrates that crystallographic tools may be promoted in the food authentication field to combat food fraud.

\section{EXPERIMENTAL}

Samples of subcutaneous adipose tissue removed from the coccyx of Iberian pigs were obtained from the Instituto Nacional de Investigación y Tecnología Agraria y Alimentaria (INIA) (Zafra, Spain). Lipid fractions were extracted and dehydrated by the LiBiFood research group of the Universitat de Barcelona, following the procedure explained elsewhere (Bayés-García et al., 2016). All lipid extracts were stored in topaz vials with liquid nitrogen inert atmosphere in the freezer to avoid oxidation. Eighty samples (20 samples for each category) were available. Before performing any analysis, samples were melted at $65^{\circ} \mathrm{C}$ and homogenized by using a vortex.

A total of 240 DSC experiments were conducted, that is three repetitions for each sample among the 80 different samples. They were performed at atmospheric pressure using a PerkinElmer Diamond. Samples (9.0-9.9 mg) were weighted into $50 \mu \mathrm{l}$ aluminum pans, and covers were sealed into place. The instrument was calibrated with reference to the enthalpy and the melting points of indium (melting temperature $156.6^{\circ} \mathrm{C} ; \Delta H=28.45 \mathrm{~J} / \mathrm{g}$ ) and decane (melting temperature $-29.7^{\circ} \mathrm{C} ; \Delta H=202.1 \mathrm{~J} / \mathrm{g}$ ) standards. An empty pan was used for reference. Dry nitrogen was used as purge gas in the DSC cell at $20 \mathrm{~cm}^{3} / \mathrm{min}$. Thermograms were analyzed using Pyris Software to obtain the enthalpy $(\mathrm{J} / \mathrm{g}$, integration of the DSC signals) and onset and end temperatures of transformations $\left({ }^{\circ} \mathrm{C}\right.$, intersection of the baseline and the initial and final tangents at the transformation). The thermal program used for all samples consisted of cooling from 65 to $-80^{\circ} \mathrm{C}$ at $2^{\circ} \mathrm{Cl}$ min followed by a subsequent heating process from -80 to $65^{\circ} \mathrm{C}$ at the same rate.

For statistical analysis of the DSC data, random uncertainty was determined with a $95 \%$ threshold of reliability using the Student's method, which enables estimating the mean of normally distributed population when the population is relatively small. Results were expressed as mean \pm associated error $(n=3)$ and as mean \pm standard deviation (SD) for each sample and for each Iberian pig category, respectively. Significant differences between categories (through crystallization and melting temperatures) were determined at $p<0.05$ according to the one-way analysis of variance (ANOVA): Post Hoc Comparisons (Tukey). These analyses were performed using SPSS Statistics 25.0 software.

In order to interpret and clarify the crystallization and polymorphic behavior observed by DSC, X-ray diffraction experiments, with both laboratory-scale and synchrotron radiation source, were performed for selected samples of each Iberian pig fat category. The X-ray diffraction results obtained by the two sources 
became equivalent. However, in this work we will describe the synchrotron data for a better clarity and resolution. Laboratory-scale powder X-ray diffraction (lab-scale XRD) measurements were performed by using a PANalytical X'Pert Pro MPD powder diffractometer equipped with a hybrid Monochromator and an $X$ 'Celerator Detector. The equipment also included an Oxford Cryostream Plus $220 \mathrm{~V}$ (temperature 50-500 K). This diffractometer operates with DebyeScherrer transmission. The sample was introduced in a $1 \mathrm{~mm}$-diameter Lindermann glass capillary that was rotated around its axis during the experiment to minimize preferential orientation of the crystallites. The step size was $0.013^{\circ}$ from $1.004^{\circ}$ to $28^{\circ} 2 \theta$, and the measuring time was 2.5 min per pattern.

Synchrotron radiation $\mathrm{X}$-ray diffraction (SR-XRD) experiments were conducted at the beamline BL11-NCD-SWEET of the Alba Synchrotron facility (Cerdanyola del Vallès, Spain) at $12.4 \mathrm{keV}$. The sample-detector distance was $2.2 \mathrm{~m}$. X-ray scattering data were collected on a Quantum 210r ADSC detector with a pixel size of $102.4 \times 102.4 \mu \mathrm{m}^{2}$ for small-angle X-ray diffraction (SAXD) data and on a LX255-HS Rayonix detector with a pixel size of $40 \times 40 \mathrm{~mm}^{2}$ for the wide-angle X-ray diffraction (WAXD) data. The exposure time was $20 \mathrm{~s}$. The temperature of the sample was controlled by a Linkam stage. SR-XRD patterns were acquired while the sample was cooled from 65 to $-80^{\circ} \mathrm{C}$ and reheated to $65^{\circ} \mathrm{C}$ at the same controlled rate. The sample was placed in an aluminum sample cell with a Kaptom film window. The $q$-axis calibration was obtained by measuring silver behenate for SAXD and $\mathrm{Cr}_{2} \mathrm{O}_{5}$ for WAXD. The software PyFAI was used to integrate the 2D WAXD into 1D data: the SAXD data were processed with in-house software.

The same selected samples for X-ray diffraction analyses were subjected to gas chromatography to roughly correlate the different crystallization behavior observed in the different Iberian pig categories with their fatty acid compositions. The equipment consisted of a Shimadzu QP2010 coupled to a SGE BPX70 column $(30 \mathrm{~m} \times 0.25 \mathrm{~mm}, 0.25 \mu \mathrm{m})$. The sample was diluted in n-hexane-dichloromethane $(5: 1)$ and carried with $\mathrm{He}$. The injector temperature was $260^{\circ} \mathrm{C}$ with split (split ratio 1:20). The mass spectroscopy coupled with the column worked with an ion injector temperature of $200^{\circ} \mathrm{C}$ and an $\mathrm{m} / \mathrm{z}$ range from 50.00 to 650.00 .

\section{RESULTS AND DISCUSSION}

\section{Thermal behavior of Iberian pig categories}

The crystallization and polymorphic behavior of lipid extracts of bellota, recebo, cebo de campo and cebo categories were determined by DSC and XRD techniques when samples were cooled from 65 to $-80^{\circ} \mathrm{C}$ at a rate of $2^{\circ} \mathrm{C} / \mathrm{min}$ and subsequently heated to $65^{\circ} \mathrm{C}$ at the same rate. A total of 240 DSC experiments were carried out. Due to the complexity of the DSC thermograms and overlapping of thermal events, we defined two main temperatures as indicators of the crystallization and melting behavior of the samples: the initial crystallization ( $T_{\text {onset }}$, from this point on $T_{\mathrm{c}}$ ), and the end of melting ( $T_{\text {end }}, T_{\mathrm{m}}$ from now) temperatures. The mean values and associated errors for the 80 different samples analyzed (20 samples for each category) are displayed in Table 2.

The results indicated an average initial crystallization temperature of $8.6 \pm 1.6^{\circ} \mathrm{C}$ and $9.6 \pm 2.9^{\circ} \mathrm{C}$ for the bellota and recebo samples, respectively. By contrast, cebo de campo and cebo samples exhibited higher onset crystallization temperatures of $15.9 \pm 1.6^{\circ} \mathrm{C}$ and $16.2 \pm 3.1^{\circ} \mathrm{C}$, respectively. Regarding the melting behavior, again comparable temperatures were detected in bellota and recebo samples, with average end temperatures of $28.0 \pm 0.7^{\circ} \mathrm{C}$ and $28.6 \pm 1.2^{\circ} \mathrm{C}$, respectively. As to cebo de campo and cebo categories, the corresponding average end melting temperature was $30.7 \pm 0.9^{\circ} \mathrm{C}$ and $30.7 \pm 1.0^{\circ} \mathrm{C}$, respectively. As confirmed by the one-way ANOVA, for both crystallization and melting temperatures, bellota and recebo were not significantly different $(p>0.05)$, and the same occurred with cebo de campo and cebo. However, significant differences existed $(p<0.05)$ between bellota and cebo de campo/cebo, and recebo and cebo de campo/cebo. Then, two clear groups can be defined, in which crystallization and melting temperatures were significantly comparable: bellota-recebo and cebo de campo-cebo. The significant differences detected through $T_{\mathrm{c}}$ were higher $(F$ factor $=55.2)$ than for $T_{\mathrm{m}}(F$ factor $=44.3)$. As to SD, they were lower for melting temperatures, as can be observed by lower dispersion in temperature values in Table 2.

The similar crystallization and melting behavior of bellota-recebo and cebo de campo-cebo samples was revealed in the corresponding DSC thermograms. As an example of the thermal behavior exhibited by each category, Figure 1 shows the DSC curves of selected samples.

All DSC thermograms consisted of four main thermal events: two exothermic peaks present in the cooling curves, and two main endothermic peaks in the heating curves. However, some differences were detected between the four categories, such as the occurrence of additional DSC signals or some shifting in temperatures at which phenomena occurred. As shown in Table 2 and Figure 1, initial and end temperatures of crystallization in bellota and recebo samples (curves (1) and (2) in Figure 2a) were significantly lower (between 7 and $10^{\circ} \mathrm{C}$ ) than those of cebo de campo and cebo samples (curves (3) and (4)). Regarding the DSC heating curves, again bellota and recebo samples exhibited a similar thermal profile, characterized by the 
T A B LE 2 Initial crystallization $\left(T_{\mathrm{c}}\right)$ and end of melting $\left(T_{\mathrm{m}}\right)$ temperatures for the 80 different samples of lipid extracts corresponding to the bellota, recebo, cebo de campo and cebo categories (20 samples for each category)

\begin{tabular}{|c|c|c|c|c|c|c|c|c|}
\hline & \multicolumn{2}{|l|}{ Bellota } & \multicolumn{2}{|l|}{ Recebo } & \multicolumn{2}{|c|}{ Cebo de campo } & \multicolumn{2}{|l|}{ Cebo } \\
\hline & $T_{\mathrm{c}}\left({ }^{\circ} \mathrm{C}\right)$ & $T_{\mathrm{m}}\left({ }^{\circ} \mathrm{C}\right)$ & $T_{\mathrm{c}}\left({ }^{\circ} \mathrm{C}\right)$ & $T_{\mathrm{m}}\left({ }^{\circ} \mathrm{C}\right)$ & $T_{\mathrm{c}}\left({ }^{\circ} \mathrm{C}\right)$ & $T_{\mathrm{m}}\left({ }^{\circ} \mathrm{C}\right)$ & $T_{\mathrm{c}}\left({ }^{\circ} \mathrm{C}\right)$ & $T_{\mathrm{m}}\left({ }^{\circ} \mathrm{C}\right)$ \\
\hline & $5.4 \pm 0.4$ & $26.8 \pm 0.5$ & $6.2 \pm 0.6$ & $26.4 \pm 0.4$ & $16.7 \pm 3.1$ & $28.0 \pm 2.1$ & $17.8 \pm 0.6$ & $30.7 \pm 0.5$ \\
\hline & $8.6 \pm 0.5$ & $27.7 \pm 0.3$ & $7.7 \pm 2.9$ & $27.4 \pm 2.9$ & $16.4 \pm 0.2$ & $31.1 \pm 0.6$ & $12.9 \pm 2.5$ & $29.2 \pm 2.1$ \\
\hline & $8.5 \pm 0.6$ & $27.8 \pm 0.3$ & $12.9 \pm 1.1$ & $30.2 \pm 1.9$ & $17.2 \pm 1.7$ & $29.7 \pm 0.6$ & $14.3 \pm 1.1$ & $29.8 \pm 0.6$ \\
\hline & $6.4 \pm 1.1$ & $26.8 \pm 0.2$ & $6.6 \pm 0.7$ & $27.9 \pm 0.7$ & $16.7 \pm 1.1$ & $30.9 \pm 0.8$ & $12.3 \pm 1.4$ & $30.0 \pm 1.2$ \\
\hline & $7.2 \pm 0.3$ & $27.6 \pm 0.7$ & $14.5 \pm 1.2$ & $29.8 \pm 0.4$ & $15.4 \pm 0.3$ & $30.1 \pm 1.1$ & $18.8 \pm 2.5$ & $32.2 \pm 2.9$ \\
\hline & $7.4 \pm 0.4$ & $27.6 \pm 0.3$ & $4.0 \pm 1.6$ & $26.4 \pm 0.3$ & $15.1 \pm 1.8$ & $30.3 \pm 1.4$ & $16.9 \pm 0.8$ & $31.9 \pm 0.9$ \\
\hline & $8.5 \pm 0.5$ & $27.8 \pm 0.5$ & $8.8 \pm 0.2$ & $28.3 \pm 0.6$ & $15.5 \pm 1.1$ & $30.1 \pm 1.5$ & $14.8 \pm 3.1$ & $29.6 \pm 1.1$ \\
\hline & $9.2 \pm 0.9$ & $28.1 \pm 0.2$ & $7.2 \pm 0.2$ & $27.8 \pm 0.6$ & $11.2 \pm 0.8$ & $29.7 \pm 0.4$ & $13.4 \pm 0.6$ & $29.4 \pm 0.4$ \\
\hline & $12.2 \pm 1.8$ & $29.9 \pm 0.4$ & $9.4 \pm 0.6$ & $29.0 \pm 0.6$ & $14.9 \pm 2.1$ & $30.6 \pm 0.9$ & $11.9 \pm 2.4$ & $29.7 \pm 0.8$ \\
\hline & $6.2 \pm 1.3$ & $27.6 \pm 4.6$ & $14.9 \pm 0.6$ & $28.7 \pm 0.6$ & $18.0 \pm 2.7$ & $31.9 \pm 2.6$ & $17.3 \pm 1.4$ & $30.5 \pm 1.9$ \\
\hline & $8.4 \pm 0.7$ & $27.7 \pm 0.8$ & $13.7 \pm 1.5$ & $30.1 \pm 2.1$ & $17.6 \pm 1.3$ & $31.5 \pm 0.7$ & $20.1 \pm 2.8$ & $31.8 \pm 3.1$ \\
\hline & $10.2 \pm 0.5$ & $27.9 \pm 0.6$ & $10.3 \pm 3.0$ & $29.5 \pm 2.0$ & $17.4 \pm 1.1$ & $31.6 \pm 0.4$ & $17.1 \pm 1.4$ & $31.2 \pm 0.7$ \\
\hline & $8.8 \pm 1.1$ & $28.2 \pm 0.3$ & $6.9 \pm 0.7$ & $27.8 \pm 0.6$ & $14.9 \pm 1.5$ & $31.0 \pm 0.6$ & $20.7 \pm 2.5$ & $32.0 \pm 2.5$ \\
\hline & $8.7 \pm 1.0$ & $28.3 \pm 1.0$ & $8.0 \pm 3.2$ & $27.4 \pm 2.0$ & $15.5 \pm 1.7$ & $31.1 \pm 0.6$ & $19.6 \pm 0.8$ & $31.6 \pm 0.3$ \\
\hline & $9.2 \pm 0.6$ & $27.9 \pm 0.9$ & $8.8 \pm 0.5$ & $28.9 \pm 0.9$ & $17.3 \pm 0.9$ & $31.8 \pm 0.3$ & $12.4 \pm 2.9$ & $29.8 \pm 0.8$ \\
\hline Mean \pm SD & $8.6 \pm 1.6 \mathrm{~d}$ & $28.0 \pm 0.7 b$ & $9.6 \pm 2.9 d$ & $28.6 \pm 1.1 b$ & $15.9 \pm 1.6 c$ & $30.7 \pm 0.9 a$ & $16.2 \pm 3.1 c$ & $30.7 \pm 1.0 a$ \\
\hline
\end{tabular}

Note: Mean values with the same letter are not significantly different $(p>0.05)$.

presence of two initial endothermic peaks with peak top temperatures between -20 and $0^{\circ} \mathrm{C}$, and complex convoluted phenomena from 10 to $25^{\circ} \mathrm{C}$. By contrast, the DSC heating curves corresponding to cebo de campo and cebo became less abrupt and continuous, as one may define just two main sharp endothermic peaks, with peak top temperatures at around 5 and $30^{\circ} \mathrm{C}$ (Figure 1b). As already stated, among all the differences observed in the DSC thermograms corresponding to the different categories, $T_{\mathrm{c}}$ and $T_{\mathrm{m}}$ were selected as indicators to discriminate among categories.

\section{Crystallographic behavior}

The different thermal behavior of the samples was interpreted by analyzing the crystallization and polymorphic behavior of the selected samples for each category as will be described further on.

Figure 2 shows SR-SAXD and SR-WAXD data obtained when a bellota sample was cooled from 65 to $-80^{\circ} \mathrm{C}$ at a rate of $2^{\circ} \mathrm{C} / \mathrm{min}$ and reheated to $65^{\circ} \mathrm{C}$ at the same rate.

During the cooling process, at a temperature of $6.3^{\circ} \mathrm{C}$, the SR-SAXD pattern revealed the occurrence of a triple chain length structure (3L) peak at $3.5 \mathrm{~nm}$. Simultaneously, in the SR-WAXD pattern, typical $\beta^{\prime}$ peaks at 0.41 and $0.38 \mathrm{~nm}$ were detected. Then, this crystallization process corresponded to a $\beta^{\prime}-3 L$ form and caused the first exothermic DSC peak occurring at around $8^{\circ} \mathrm{C}$ (peak top temperature, see Figure 1acurve (1)). At $-15.5^{\circ} \mathrm{C}$, a double chain length structure peak (2L) at $4.3 \mathrm{~nm}$ appeared in the SR-SAXD pattern accompanied by a SR-WAXD peak at $0.39 \mathrm{~nm}$, which may correspond to a $\beta^{\prime}-2 \mathrm{~L}$ form crystallization. This crystallization process may be attributable to the exothermic peak with peak top temperature at around $-10^{\circ} \mathrm{C}$ (Figure 1a-curve (1)). On further cooling, at $-21.5^{\circ} \mathrm{C}$, two extra SR-WAXD peaks occurred at 0.42 and $0.41 \mathrm{~nm}$, probably due to the crystallization of an additional $\beta^{\prime}-2 \mathrm{~L}$ polymorphic form. This phenomenon may correspond to the last DSC peak at $-21^{\circ} \mathrm{C}$ observed when cooling. During the subsequent heating process, at $-2.5^{\circ} \mathrm{C}$, the $\beta^{\prime}-2 \mathrm{~L}$ form peaks at 0.42 , 0.41 and $0.39 \mathrm{~nm}$ vanished, while the intensity of the $2 \mathrm{~L}$ peak at $4.3 \mathrm{~nm}$ considerably decreased. This SR-SAXD peak completely disappeared at $5.4^{\circ} \mathrm{C}$. These changes may be due to the melting of the two $\beta^{\prime}-2 L$ forms previously crystallized, and they may correspond to the two broad endothermic DSC peaks with 
(a)



(b)



FIGURE 1 DSC cooling (a) and subsequent heating (b) thermograms of bellota (1), recebo (2), cebo de campo (3) and cebo (4) samples when cooled from 65 to $-80^{\circ} \mathrm{C}$ at $2^{\circ} \mathrm{C} / \mathrm{min}$ and heated to $65^{\circ} \mathrm{C}$ at the same rate maximum temperatures of -12 and $0^{\circ} \mathrm{C}$. On further heating, at $17.4^{\circ} \mathrm{C}$, the SR-SAXD peak at $3.5 \mathrm{~nm}$ vanished, together with the SR-WAXD peaks at 0.41 and $0.38 \mathrm{~nm}$, due to the melting of the $\beta^{\prime}-3 \mathrm{~L}$ form. Soon after, new peaks at 4.4 and $0.46 \mathrm{~nm}$ occurred, which may correspond to a newly-formed most stable $\beta$ - $2 \mathrm{~L}$ polymorph, probably through melt-mediation after the melting of $\beta^{\prime}-2 \mathrm{~L}$ forms. This most stable form finally melted at around $39.2^{\circ} \mathrm{C}$ (see enlarged figure in Figure 2), temperature at which no peaks were present in the SR-XRD patterns, that is in accordance with the corresponding DSC thermograms. One may note the presence of a last and very flat endothermic signal in the corresponding DSC thermogram (see curve (1) in Figure 1b), which is related to the melting of this most stable $\beta-2 L$ form.

The polymorphic behavior of recebo samples was highly similar to that of bellota samples, as shown in Figure 3.
By cooling the molten recebo sample at a rate of $2{ }^{\circ} \mathrm{C} / \mathrm{min}$, triple chain length structure peak at $3.5 \mathrm{~nm}$ (SR-SAXD) and short spacing values of 0.41 and $0.38 \mathrm{~nm}$ (SR-WAXD) occurred at $2.4^{\circ} \mathrm{C}$, corresponding to the crystallization of a $\beta^{\prime}-3 \mathrm{~L}$ form. This event may correspond to the exothermic DSC signal with peak top temperature of $5^{\circ} \mathrm{C}$ (see Figure 1a). On further cooling, at $-21.4^{\circ} \mathrm{C}$, a $2 \mathrm{~L}$ structure peak at $4.3 \mathrm{~nm}$ was observed in the SR-SAXD pattern and, simultaneously, $\beta^{\prime}$ WAXD peaks at $0.44,0.43$ and $0.39 \mathrm{~nm}$ were detected ( $\beta^{\prime}-2 \mathrm{~L}$ form crystallization). Finally, at a lower temperature of $-27.5^{\circ} \mathrm{C}$, an additional peak at $0.42 \mathrm{~nm}$ appeared, which most probably corresponded to the crystallization of another $\beta^{\prime}-2 \mathrm{~L}$ form. These crystallization processes of $\beta^{\prime}-2 L$ forms may be attributable to the exothermic DSC events with maximum temperatures of -12 and $-25^{\circ} \mathrm{C}$ of the related cooling thermogram (see curve (2) in Figure 1a). As to the heating step, when 



FIG URE 2 SR-SAXD (a) and SR-WAXD (b) patterns obtained when bellota sample was cooled from 65 to $-80^{\circ} \mathrm{C}$ at $2^{\circ} \mathrm{C} / \mathrm{min}$ and reheated to $65^{\circ} \mathrm{C}$ at the same rate. D-spacing values are given in $\mathrm{nm}$

the completely crystallized recebo sample was heated at $2^{\circ} \mathrm{C} / \mathrm{min}$, the first observable change took place at $5.4^{\circ} \mathrm{C}$, temperature at which a $\beta^{\prime}-2 \mathrm{~L}$ form melted (vanishing of the SR-WAXD peaks at $0.44,0.43$ and $0.39 \mathrm{~nm}$ and decrease of the intensity of the SR-SAXD peak at $4.3 \mathrm{~nm}$ ). Within the temperature range from 11.4 to $17.3^{\circ} \mathrm{C}$, all the SR-XRD peaks vanished, so that one may deduce that $\beta^{\prime}-2 \mathrm{~L}$ and $\beta^{\prime}-3 \mathrm{~L}$ forms melted. Soon after, new SR-SAXD peak at $4.4 \mathrm{~nm}$ appeared (see enlarged figure in Figure 3 ) and, simultaneously, typical $\beta$ SR-WAXD peak was observed at $0.46 \mathrm{~nm}$. Then, one may conclude that, similarly to the bellota sample case, melt-mediated transformation occurred to obtain most stable $\beta-2 L$ form, which finally melted at around $35.2^{\circ} \mathrm{C}$ (see very flat endothermic DSC peak with peak top temperature of about $35^{\circ} \mathrm{C}$ in curve (2) of Figure $1 \mathrm{~b})$. Recebo sample exhibited, therefore, a very similar polymorphic behavior to that of bellota. However, crystallization and melting temperatures were


FIG URE 3 SR-SAXD (a) and SR-WAXD (b) patterns obtained when recebo sample was cooled from 65 to $-80^{\circ} \mathrm{C}$ at $2^{\circ} \mathrm{C} / \mathrm{min}$ and reheated to $65^{\circ} \mathrm{C}$ at the same rate. D-spacing values are given in nm

lower in recebo than in bellota in this specific case, which is in accordance with the higher dispersion and SD values of crystallization and melting temperatures of recebo samples obtained by DSC analyses (see Table 2).

Different crystallization and polymorphic behavior was detected in the cebo de campo and cebo samples. Figure 4 shows the SR-XRD data corresponding to cebo de campo, which allowed the identification of the thermal phenomena observed by DSC (curve (3) in Figure 1).

When cooled, an initial concurrent crystallization of $\beta^{\prime}-2 \mathrm{~L}$ and $\beta^{\prime}-3 \mathrm{~L}$ forms was detected at $16.3^{\circ} \mathrm{C}$. These events were related to the DSC exothermic peak with maximum temperature of $13^{\circ} \mathrm{C}$. These forms were identified by long spacing values of 4.9 and $3.5 \mathrm{~nm}$, respectively, and short spacing values of 0.41 and $0.38 \mathrm{~nm}$. On further cooling, at $-11.5^{\circ} \mathrm{C}$, the SR-SAXD pattern showed the occurrence of an additional $2 \mathrm{~L}$ peak at $4.3 \mathrm{~nm}$ and, at $-15.5^{\circ} \mathrm{C}$, the SR-WAXD pattern exhibited two new peaks at 0.43 and $0.39 \mathrm{~nm}$, which may refer to the formation of an additional $\beta^{\prime}-2 \mathrm{~L}$ form or 



F I G U RE 4 SR-SAXD (a) and SR-WAXD (b) patterns obtained when cebo de campo sample was cooled from 65 to $-80^{\circ} \mathrm{C}$ at $2{ }^{\circ} \mathrm{C} / \mathrm{min}$ and reheated to $65^{\circ} \mathrm{C}$ at the same rate. D-spacing values are given in $\mathrm{nm}$

two additional $\beta^{\prime}-2 \mathrm{~L}$ forms, as will be justified through the heating step. Regarding the DSC cooling thermogram, these phenomena may correspond to the second main exothermic peak with peak top temperature at around $-10^{\circ} \mathrm{C}$. During the heating process, the first observable change took place at $3.5^{\circ} \mathrm{C}$, when the $0.39 \mathrm{~nm}$ peak disappeared, due to the melting of one of the newly-formed $\beta^{\prime}-2 \mathrm{~L}$ forms (on the DSC heating thermogram, this process was related to the endothermic event with $T_{\max }=2^{\circ} \mathrm{C}$ ). At $25.3^{\circ} \mathrm{C}$, the $4.9 \mathrm{~nm}$ peak disappeared, at $27.3^{\circ} \mathrm{C}$ the peaks at $0.43,0.41$ and $0.38 \mathrm{~nm}$ also vanished and, soon after, at $31.3^{\circ} \mathrm{C}$ the peak at $3.5 \mathrm{~nm}$ also disappeared. These phenomena corresponded to the melting of the remaining $\beta^{\prime}-2 L$ forms and $\beta^{\prime}-3 \mathrm{~L}$ form. Then, at $33.2^{\circ} \mathrm{C}$, the peak at $4.3 \mathrm{~nm}$ vanished and a new peak at $4.4 \mathrm{~nm}$ occurred in the SR-SAXD pattern, together with a SR-WAXD peak at $0.46 \mathrm{~nm}$, indicating the crystallization of a most stable $\beta-2 L$ form, most probably through a melt-mediated process. Finally, at a temperature of $43.2^{\circ} \mathrm{C}$, no SR-XRD peaks were present, and the melting of most
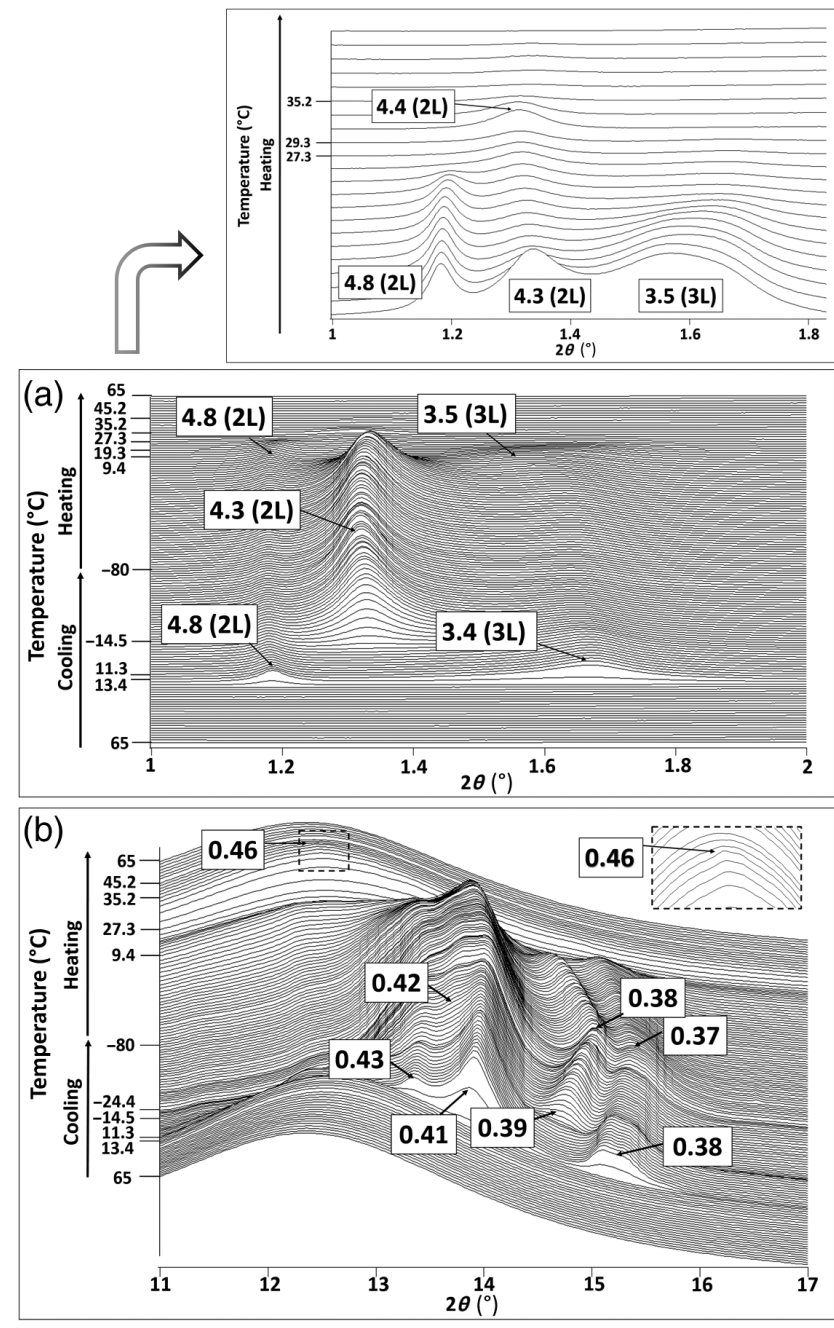

FIG URE 5 SR-SAXD (a) and SR-WAXD (b) patterns obtained when cebo sample was cooled from 65 to $-80^{\circ} \mathrm{C}$ at $2^{\circ} \mathrm{C} / \mathrm{min}$ and reheated to $65^{\circ} \mathrm{C}$ at the same rate. D-spacing values are given in nm

stable $\beta-2 \mathrm{~L}$ form may be related to the flat endothermic DSC peak with maximum temperature of around $40^{\circ} \mathrm{C}$, observable in curve (3) of Figure $1 \mathrm{~b}$.

The selected cebo sample was subjected to the same thermal treatment and the SR-XRD patterns obtained are shown in Figure 5.

When cooled from 65 to $-80^{\circ} \mathrm{C}$ at a rate of $2^{\circ} \mathrm{C} / \mathrm{min}$, the SR-SAXD pattern exhibited, at $13.4^{\circ} \mathrm{C}$, the occurrence of an initial peak at $4.8 \mathrm{~nm}(2 \mathrm{~L})$ and, simultaneously, the SR-WAXD pattern showed the formation of typical $\beta^{\prime}$ form peaks at 0.41 and $0.38 \mathrm{~nm}\left(\beta^{\prime}-2 \mathrm{~L}\right.$ form crystallization). Soon after, at $11.3^{\circ} \mathrm{C}$, a SR-SAXD peak at $3.4 \mathrm{~nm}(3 \mathrm{~L})$ accompanied by SR-WAXD peaks at 0.43 and $0.38 \mathrm{~nm}$ were detected, due to the crystallization of a $\beta^{\prime}-3 \mathrm{~L}$ polymorph. These two crystallization processes ( $\beta^{\prime}-2 L$ and $\beta^{\prime}-3 L$ forms) may be related to the first observable exothermic DSC peak with peak top temperature of about $17^{\circ} \mathrm{C}$ (curve (4) in Figure 1a). Then, at $-14.5^{\circ} \mathrm{C}$, an additional $\beta^{\prime}-2 \mathrm{~L}$ form crystallized, with long and short spacing values of 4.3 and $0.39 \mathrm{~nm}$. 
This last event may correspond to the DSC exothermic peak at $T_{\max }=-9^{\circ} \mathrm{C}$. Finally, at $-24.4^{\circ} \mathrm{C}$, the SRWAXD pattern indicated the occurrence of a $\beta^{\prime}$ form peak at $0.42 \mathrm{~nm}$ (observed on the DSC cooling curve at $T_{\max }=-23^{\circ} \mathrm{C}$ ). Nevertheless, the chain length structure of this newly formed polymorph could not be determined due to the overlapping of the peaks. During the subsequent heating stage, the first melting phenomenon corresponded to the lastly formed $\beta^{\prime}-2 \mathrm{~L}$ form and it was observed at $9.4^{\circ} \mathrm{C}$, temperature at which the SRWAXD peak at $0.39 \mathrm{~nm}$ vanished and the intensity of the SR-SAXD peak at $4.3 \mathrm{~nm}$ decreased significantly. This event may be related to the first important endothermic DSC signal with peak top temperature of around $4^{\circ} \mathrm{C}$. According to the SR-XRD data, at $27.3^{\circ} \mathrm{C}$, the initially formed $\beta^{\prime}-2 \mathrm{~L}$ form and the $\beta^{\prime}$ form with no definite long spacing value melted (peaks at 4.8, 0.42, 0.41 and $0.38 \mathrm{~nm}$ ). Later, at $29.3^{\circ} \mathrm{C}$, the peak at $3.5 \mathrm{~nm}$ disappeared, which may be attributed to the melting of $\beta^{\prime}-3 L$ form. These melting processes were related to the second main endothermic signals with maximum temperature of about $29^{\circ} \mathrm{C}$. Further on, and similarly to other Iberian categories, at $35.2^{\circ} \mathrm{C}$, most stable $\beta-2 \mathrm{~L}$ form occurred, with long and short spacing values of 4.4 and $0.46 \mathrm{~nm}$, respectively. This most stable form finally melted at $45.2^{\circ} \mathrm{C}$, temperature at which no peaks were present. In the case of cebo sample, the last flat endothermic DSC peak with maximum temperature of about $40^{\circ} \mathrm{C}$, which may correspond to the melting of most stable $\beta-2 L$ form, becomes more pronounced than for other categories.

The polymorphic behavior of cebo de campo and cebo samples became highly similar, as will be discussed further on.

Although SR-XRD provided accurate structural information and resolution, which permitted to carefully interpret the complex polymorphic behavior of Iberian pig lipid extracts, lab-scale XRD was also applied to the selected samples and the results obtained were highly equatable with those obtained with synchrotron radiation source, as shown in Figure 6.

Not surprisingly, weakest peaks detected by SR-XRD, such as that at $0.46 \mathrm{~nm}$ corresponding to most stable $\beta$ form, occurring at the end of the heating process, was not observed in all samples by using lab-scale XRD. However, most significant polymorphic events examined with lab-scale radiation source became equivalent to those determined when synchrotron radiation was applied. Initial polymorphic crystallization processes became especially meaningful to discriminate among categories, as will be discussed through the manuscript, and this could be equally achieved by the two sources. All samples of lipid extracts belonging to the different Iberian pig categories of bellota, recebo, cebo de campo and cebo exhibited highly complex polymorphic behavior at the experimental conditions examined. This complexity was detected in the corresponding DSC cooling and heating thermograms, but also in the SR-XRD patterns. As to the thermal behavior of the samples, the occurrence of overlapped endothermic and exothermic DSC phenomena predominated, often taking place continuously throughout all the thermal profile. The same happened with SR-XRD data, in which concurrent crystallization of multiple polymorphic forms with similar short-spacing values created meaningful difficulties in the identification of polymorphic forms. However, SR-SAXD patterns facilitated this task.

As a summary, Figure 7 depicts the polymorphic behavior determined for the four Iberian pig categories.

SR-XRD data confirmed the tendencies observed in the DSC thermograms of the samples. The four Iberian pig categories could be arranged in two main groups: that formed by bellota and recebo, and that constituted by the cebo de campo and cebo categories. Bellota and recebo samples exhibited a simpler polymorphic behavior compared to that of cebo de campo and cebo. When the two samples were cooled from the molten state, three different polymorphic forms crystallized: an initial $\beta^{\prime}-3 L$ form followed by two different $\beta^{\prime}-2 L$ forms. Then, when heated, these forms melted, and some fraction of the liquid crystallized to obtain most stable $\beta-2 \mathrm{~L}$ form, which finally melted at a temperature of about $35-40^{\circ} \mathrm{C}$. By contrast, cebo de campo and cebo samples crystallized in a higher number of polymorphic forms. The first characteristic event was the initial crystallization of a $\beta^{\prime}-2 \mathrm{~L}$ form with a long spacing value of 4.8 or $4.9 \mathrm{~nm}$, which was not detected in bellota and recebo samples. This additional polymorphic crystallization may be directly related to the higher crystallization and melting temperatures exhibited by cebo de campo and cebo samples. The phenomenon was followed by the occurrence of a $\beta^{\prime}-3 L$ form and at least two more $\beta^{\prime}-2 L$ forms. When samples were heated, and similarly to the bellotarecebo case, these polymorphs melted and some liquid fraction re-crystallized to obtain most stable $\beta$ - $2 \mathrm{~L}$ form through melt-mediation. This most stable form melted at around $43-45^{\circ} \mathrm{C}$, temperature significantly higher than that corresponding to bellota and recebo samples (temperatures below $40^{\circ} \mathrm{C}$ ). As stated, the most distinctive and representative characteristic to discriminate among categories were initial crystallization and end of melting temperatures, which became higher in cebo de campo and cebo samples compared to bellota and recebo. However, as confirmed by the one-way ANOVA, differences detected in the initial crystallization temperature became more significant than those associated to the end of melting in order to discriminate among categories. Furthermore, in general bellota and recebo categories exhibited sharper and better-defined exothermic and endothermic signals, whereas the phenomena showed by cebo de campo and cebo categories became more continuous through all the thermal program applied due to the occurrence of a higher number of polymorphic forms which may be overlapping. 

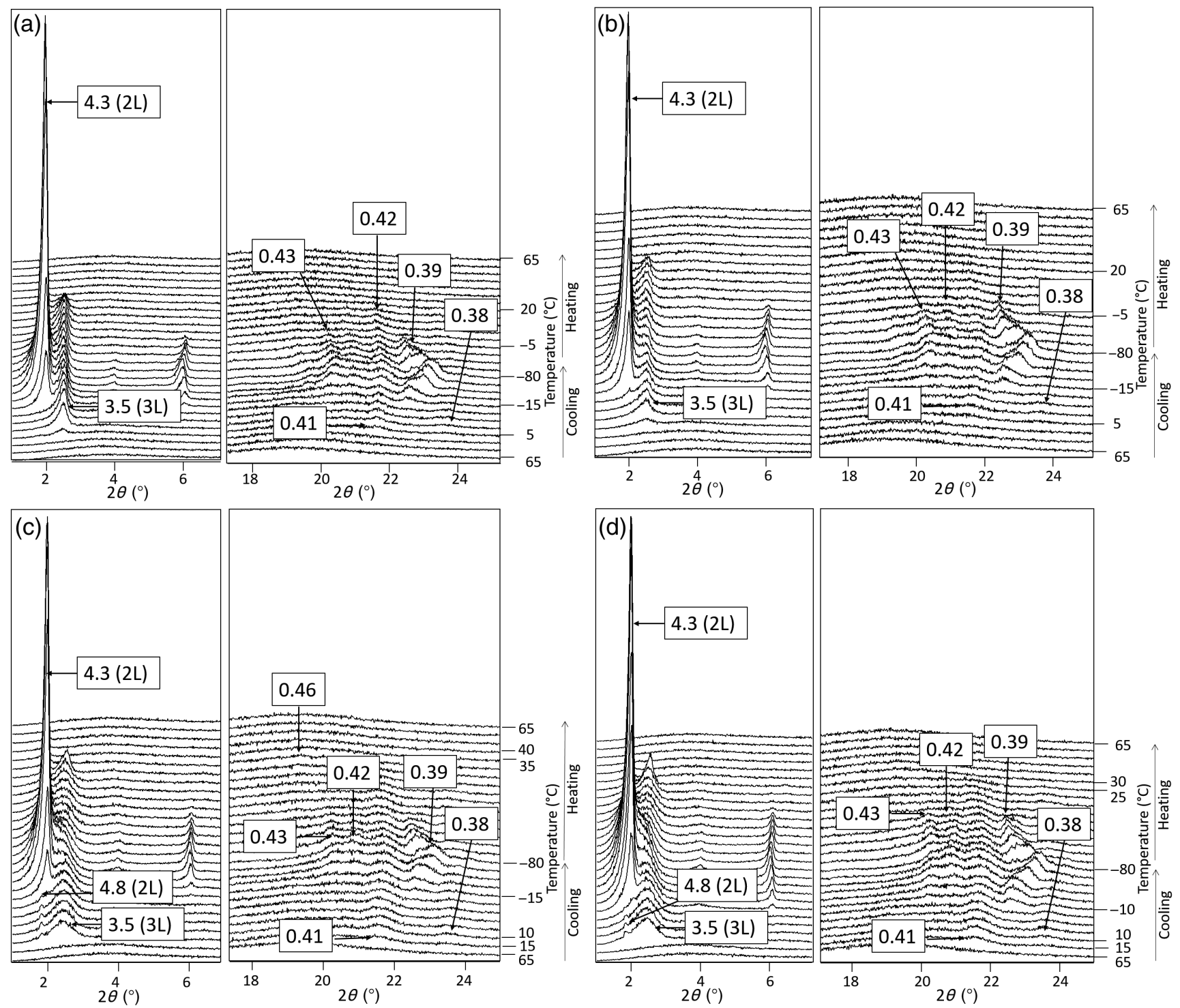

F I G U R E 6 Lab-scale XRD patterns obtained when (a) bellota, (b) recebo, (c) cebo de campo, and (d) cebo samples were cooled from 65 to $-80^{\circ} \mathrm{C}$ at $2^{\circ} \mathrm{C} / \mathrm{min}$ and reheated to $65^{\circ} \mathrm{C}$ at the same rate. $\mathrm{D}$-spacing values are given in $\mathrm{nm}$

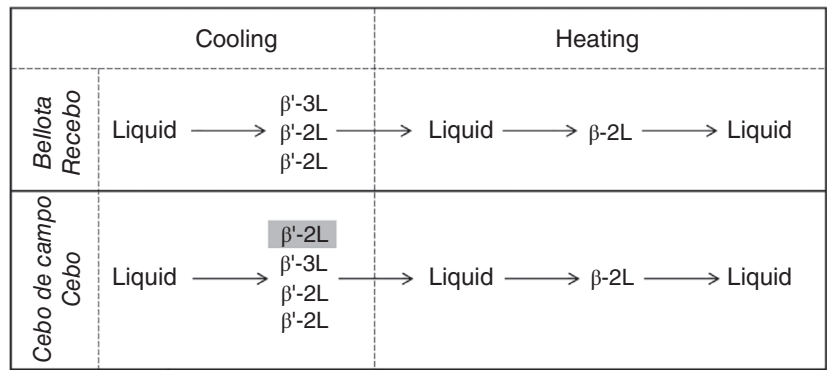

F IG URE 7 Polymorphic crystallization and transformation of Iberian pig categories

\section{Fatty acids composition}

Besides the different polymorphic crystallization observed in the two groups of Iberian categories, characterized by an initial crystallization of a $\beta^{\prime}-2 L$ form in cebo de campo and cebo categories, the higher crystallization and melting temperatures determined in the samples belonging to these two categories may also be associated with a more saturated composition of fatty acid moieties, as we confirmed by chromatographic techniques. Figure 8 depicts the distribution of main fatty acids in lipid extracts of the bellota $(B)$, recebo $(R)$, cebo de campo $(C C)$ and cebo $(C)$ selected samples.

The results showed that the main fatty acid was monounsaturated oleic acid (within the range 50\%-60\%) for all categories, followed by saturated palmitic $(17 \%-$ $24 \%)$ and stearic $(7 \%-12 \%)$ acids, diunsaturated linoleic acid $(7 \%-9 \%)$, monounsaturated palmitoleic acid $(1 \%-$ $3 \%)$ and saturated myristic acid (1\%-2\%). These results were in agreement with those reported by Diaz et al. (1996) and Gallardo et al. (2012) who defined POO, 


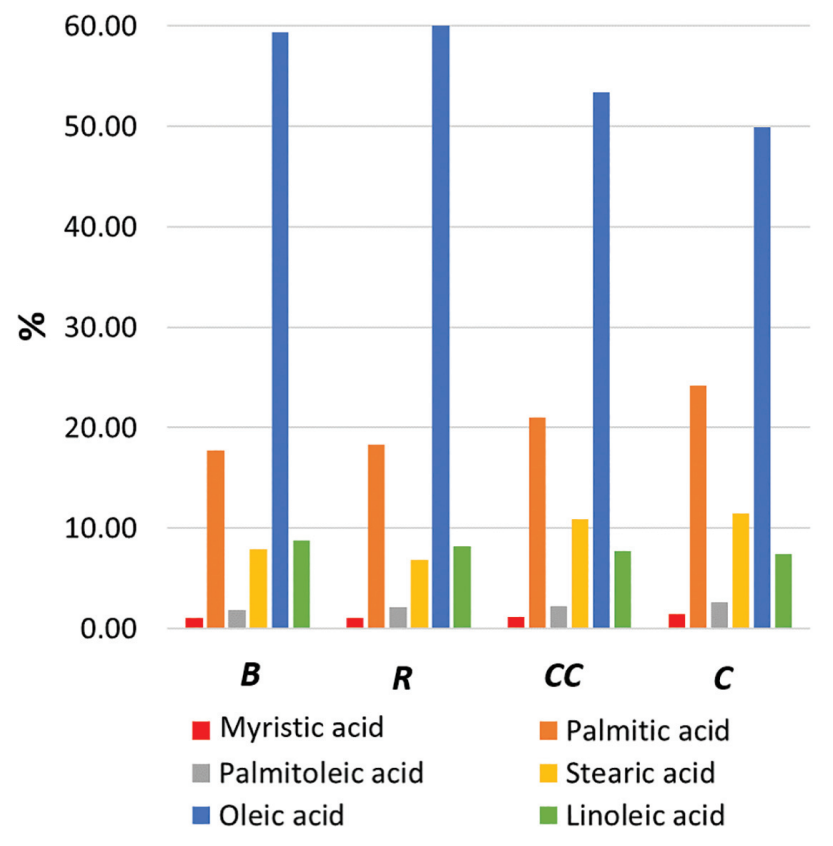

F I G URE 8 Fatty acids distribution per weight (\%) of lipid extracts of bellota $(B)$, recebo $(R)$, cebo de campo $(C C)$ and cebo $(C)$ samples

OOO, POL and POS as main triacylglycerol components of lberian pig fat.

By comparing the lipid extracts compositions of the four categories, one may define a clear tendency which is related to the saturated/unsaturated nature of the three main fatty acids (oleic, palmitic and stearic). The percentage of unsaturated oleic acid decreased, whereas those of saturated palmitic and stearic increased in the sequence bellota $(B)$-recebo $(R)$-cebo de campo (CC)-cebo (C).

Although, as expected, some differences in fatty acid compositions were detected, one may take into account that variations in the polymorphic behavior may be mostly dictated by TAGs molecular structures (and resulting interactions), in which fatty acids can occupy different positions in the glycerol backbone.

\section{Driving factors for the polymorphic behavior of Iberian pig categories}

By considering the characteristics that define each lberian pig category, regarding the feeding system during the fattening phase (consumption of acorns and/or concentrated feed), grazing (that is, doing physical exercise), and so on one may extract some conclusions about which are the driving factors that determine the polymorphism of their lipid extracts. Figure 9 summarizes these distinctive characteristics associated to the rearing system and grazing for the four categories.

The results presented in this work demonstrated that bellota and recebo samples exhibited essentially the same polymorphic behavior, and the same occurred to cebo de



FIG URE 9 Summary of the characteristics of the different rearing systems of Iberian pigs

campo and cebo categories. As shown in Figure 9, distinctive characteristics of both bellota and recebo are the consumption of acorns and grazing, which involves physical exercise. Grazing becomes another characteristic activity of cebo de campo, similarly to the commercial feed consumption, which is common in recebo, cebo de campo and cebo categories. Thus, one may conclude that the key factor which determines the polymorphic behavior of Iberian pig lipid extracts is not the physical exercise practiced by the pig, but the inclusion of acorns in the feeding system. In this sense, the polymorphic behavior may be used as a tool to discriminate among some of the Iberian pig categories. In our previous work (Bayés-García et al., 2016) we concluded that both DSC and XRD techniques could be used as identification methods to discriminate among the two most differentiated categories: bellota and cebo categories. In the present manuscript we showed that it is also possible to discriminate among intermediate categories of recebo and cebo de campo, as recebo samples exhibit an equivalent behavior to that of bellota, whereas cebo de campo becomes highly similar to cebo. With the present work we do not expect to validate an authentication method, as further work may be needed to analyze a higher number of samples of all categories. Nevertheless, it becomes a good approach to show another application of the polymorphic study of lipid samples, which is its use for the discrimination among different product categories and, therefore, to combat food fraud.

\section{CONCLUSIONS}

DSC and XRD techniques were used with the objective of discriminating among different categories of Iberian pig lipid extracts. Cebo de campo and cebo categories exhibited higher crystallization and melting temperatures, which was strongly related to an initial crystallization of a $\beta^{\prime}-2 \mathrm{~L}$ form, not detected in bellota and recebo. By considering the differences in rearing systems of pigs belonging to the different categories, we concluded that the key factor which determined the polymorphic behavior of Iberian pig lipid extracts was not the physical exercise practiced by the pig, but the 
inclusion of acorns in the feeding system. Although further work is needed to analyze a higher number of samples of all categories to confirm the results presented, with this work we showed that techniques usually used for polymorphic characterization, such as DSC and $X R D$, may be promoted to be used as fingerprinting tools for food products authentication.

\section{ACKNOWLEDGMENTS}

The authors would like to thank the financial support of the Ministerio de Economía y Competitividad through Project No. MAT2015-65756-R. Funding from the Alba synchrotron facility for performing SR-XRD experiments is gratefully appreciated. SR-XRD experiments were conducted with the approval of the Alba Scientific Advisory Committee (Proposal No. 2014070991). The authors thank Dr. Marc Malfois, responsible for BL11-NCDSWEET at Alba, for his help. They also acknowledge Dr. Juan M. García-Casco from the Instituto Nacional de Investigación y Tecnología Agraria y Alimentaria (INIA) for providing the lberian pig fat samples.

\section{CONFLICT OF INTEREST}

The authors declare that they have no conflict of interest.

\section{AUTHOR CONTRIBUTIONS}

Laura Bayés-García: Performed the design of the study, experimental procedures execution, data interpretation, and manuscript preparation. Eduard Colomer-Llombart and Mercedes Aguilar-Jiménez: Contributed to the experimental part and data interpretation. Teresa Calvet: contributed to the design of the study and critical manuscript revision.

\section{ETHICS STATEMENT}

This research did not involve any human or animal study and institutional ethical approval was not required.

\section{ORCID}

\section{Laura Bayés-García (1) https://orcid.org/0000-0003- 1481-581X}

\section{REFERENCES}

Arce L, Domínguez-Vidal A, Rodríguez-Estévez V, López-Vidal S, Ayora-Cañada MJ, Valcárcel M. Feasibility study on the use of infrared spectroscopy for the direct authentication of Iberian pig fattening diet. Anal Chim Acta. 2009;636:183-9.

Bayés-García L, Tres A, Vichi S, Calvet T, Cuevas-Diarte MA, Codony R, et al. Authentication of Iberian dry-cured ham: new approaches by polymorphic fingerprint and ultrahigh resolution mass spectrometry. Food Control. 2016;60:370-7.

Bayés-García L, Sato K, Ueno S. Polymorphism of triacylglycerols and natural fats. Bailey's industrial oil and fat products. Hoboken, NJ: Wiley; 2020.

Campos R, Narine SS, Marangoni AG. Effect of cooling rate on the structure and mechanical properties of milk fat and lard. Food Res Int. 2002;35:971-81.
Chiavaro E, Rodriguez-Estrada MT, Barnaba C, Vittadini E, Cerretani L, Bendini A. Differential scanning calorimetry: a potential tool for discrimination of olive oil comercial categories. Anal Chim Acta. 2008a;625:215-26.

Chiavaro E, Vittadini E, Rodriguez-Estrada MT, Cerretani L, Bendini A. Differential scanning calorimeter application to the detection of refined hazelnut oil in extra virgin olive oil. Food Chem. 2008b;110:248-56.

Cordella C, Moussa I, Martel AC, Sbirrazzuoli N, Lizzani-Cuvelier L. Recent developments in food characterization and adulteration detection: techniques-oriented perspectives. J Agric Food Chem. 2002;50:1751-64.

Davenel A, Riaublanc A, Marchal P, Gandemer G. Quality of pig adipose tissue: relationship between solid fat content and lipid composition. Meat Sci. 1999;51:73-9.

Diaz I, García Regueiro JA, Casillas M, De Pedro E. Triglyceride composition of fresh ham fat from Iberian pigs produced with different systems of animal nutrition. Food Chem. 1996;55: 383-7.

Ellis DI, Brewster VL, Dunn WB, Allwood JW, Golovanov AP, Goodacre R. Fingerprinting food: current technologies for the detection of food adulteration and contamination. Chem Soc Rev. 2012;41:5706-27.

Gallardo E, Narváez-Rivas M, Pablos F, Jurado JM, León-Camacho M. Subcutaneous fat triacylglycerols profile from Iberian pigs as a tool to differentiate between intensive and extensive fattening systems. J Agric Food Chem. 2012;60:1645-51.

González-Martin I, González-Pérez C, Hernández Méndez J, Marqués-Macias E, Sanz Poveda F. Use of isotope analysis to characterize meat from Iberian-breed swine. Meat Sci. 1999;52: 437-41.

Larsson K, Quinn P, Sato K, Tiberg F. Lipids: structure, physical properties and functionality. Bridgwater: The Oily Press; 2006.

Motoyama M, Ando M, Sasaki K, Hamaguchi H. Differentiation of animal fats from different origins: use of polymorphic features detected by Raman spectroscopy. Appl Spectrosc. 2010;64: 1244-50.

Motoyama M, Chikuni K, Narita T, Aikawa K, Sasaki K. In situ Raman spectrometric analysis of crystallinity and Cristal polymorphism of fat in porcine adipose tissue. J Agric Food Chem. 2013;61: 69-75.

Narváez-Rivas M, Rios JJ, Arteaga JF, Quilez JF, Barrero AF, León-Camacho M. Determination of ent-kaurene in subcutaneous fat of Iberian pigs by gas chromatography multi-stage mass spectrometry with the aim to differentiate between intensive and extensive fattening systems. Anal Chim Acta. 2008;624:107-12.

Narváez-Rivas M, Pablos F, Jurado JM, León-Camacho M. Authentication of fattening diet of Iberian pigs according to their volatile compounds profiles from raw subcutaneous fat. Anal Bioanal Chem. 2011;399:2115-22.

Petrón MJ, Muriel E, Timón ML, Martín L, Antequera T. Fatty acids and triacylglycerols profiles from different types of Iberian dry-cured hams. Meat Sci. 2004;68:71-7.

Royal Decree 4/2014. Approves the quality standards for the Iberian meat, ham, shoulders and loin (pp. 1569-1585). BOE, No. 10 (January 11, 2014).

Ruiz J, Cava R, Antequera T, Martín L, Ventanas J, López-Bote J. Prediction of the feeding background of Iberian pigs using the fatty acid profile of subcutaneous, muscle and hepatic fat. Meat Sci. 1998;49:155-63.

Svenstrup G, Brüggemann D, Kristensen L, Risbo J, Skibsted LH. The influence of pretreatment on pork fat crystallization. Eur $\mathrm{J}$ Lipid Sci Technol. 2005;107:607-15.

Tejeda JF, Gandemer G, Antequera T, Viau M, García C. Lipid traits of muscles as related to genotype and fattening diet in Iberian 
pigs: total intramuscular lipids and triacylglycerols. Meat Sci. 2002;60:357-63.

Timón ML, Ventanas J, Carrapiso Al, Jurado A, García C. Subcutaneous and intermuscular fat characterization of dry-cured Iberian hams. Meat Sci. 2001;58:85-91.

Viera-Alcaide I, Vicario IM, Escudero-Gilete ML, Graciani Constante E, León-Camacho M. A multivariate study of the triacylglycerols composition of the subcutaneous adipose tissue of Iberian pig in relation to the fattening diet and genotype. Grasas Aceites. 2008;59:327-36.
How to cite this article: Bayés-García $L$, Colomer-Llombart E, Aguilar-Jiménez M, Calvet T. Polymorphic fingerprint as an approach to authenticate Iberian pig categories. J Am Oil Chem Soc. 2021;98:1093-105. https://doi.org/10. 1002/aocs. 12543 